\title{
Property Risk, Foreclosure Costs and Rational Lending Discrimination
}

\author{
David Nickerson \\ Rogers School of Management, Ryerson University, \\ Toronto, Ontario, Canada \\ Tel: 1-416-979-5000Ｅ-mail: dbnickerson@ryerson.ca \\ David Scofield \\ Rogers School of Management, Ryerson University, \\ Toronto, Ontario, Canada \\ Tel: 1-416-979-5000Ｅ-mail: dscofield@ryerson.ca
}

Received: Sept. 30, 2016

doi:10.5296/ifb.v4i1.10089
Accepted: Oct. 31, 2016 Published: May 3, 2017

URL: http://dx.doi.org/10.5296/ifb.v4i1.10089

\begin{abstract}
Observations of significant differences in access to credit, loan terms and the volume of lending between demographically distinct groups of borrowers are often interpreted as evidence of potential ethnic, racial or gender discrimination by lenders. The competitive structure of credit markets and the accuracy of measuring individual credit risk render extant models of lending discrimination based on assumptions of credit market inefficiencies, such as adverse selection, increasingly implausible. In stark contrast to existing models of demographic discrimination, we consider a model of mortgage lending in an economy having complete markets, common knowledge and arbitrage-free pricing. Market equilibria in this classical environment may exhibit discrimination even when borrowers, who are distinguished only by observable demographic traits, share an identical measure of individual credit risk. Relatively costlier loan terms, a higher frequency of loan denials, or a complete rationing of credit to a particular demographic class of borrowers may be a value-maximizing strategy when rational lenders perceive that one or more such traits are directly related to adverse features of the representative property securing the loan to a borrower in this class. Omitted from standard statistical underwriting and regulatory review procedures, these features reduce the value of the collateral available to the lender in the event of future default.
\end{abstract}




\section{Macrothink}

International Finance and Banking

ISSN 2374-2089

2017, Vol. 4, No. 1

When loans are secured by such properties and both lenders and borrowers act strategically, discrimination on this basis will be a property of all market equilibria and can be consistent with an efficient allocation of credit.

Keywords: Credit rationing, Discrimination, Efficient markets, Perfect equilibria 


\section{Introduction}

Virtually all empirical studies of mortgage and consumer lending in the United States conclude that minority borrowers appear to encounter significantly different loan terms, higher rates of loan denials and even explicit credit rationing than do other borrowers to whom they appear identical in their measure of credit risk. Evidence of such lending discrimination, particularly in regard to residential mortgages, poses a significant anomaly for rationality and efficiency in the classical model of credit markets. (Note 1)

Two different explanations for this evidence are most often given, each depending on implicit or explicit situations of market failure. The first, popular among policymakers and the public, asserts that lender preferences over demographic traits of borrowers are the primary cause of discrimination. These preferences either violate the criteria for economic rationality, are biased against certain borrowers owing to demographic traits that appear unrelated to credit risk, or are affected by behavioral limits on cognition which lead to suboptimal loan decisions. (Note 2) Assuming lenders possess market power, such preferences could lead to systematic discrimination between borrowers in several forms, including significant variation in loan terms and even the rationing of credit through systematic denials of loan applications.

Traditional economic explanations, in contrast, involve in efficiencies affecting loan underwriting, due either to exogenous constraints on the accurate pricing of individual credit risk or to the assumption of an asymmetric dispersion of information across lenders and borrowers. Both adverse selection and moral hazard, for example, can produce dispersion in loan terms, denial rates and the rationing of credit across distinct groups of borrowers who differ by unobservable probabilities of default. (Note 3) The competitive structure of most credit markets, the availability of credit histories and the widespread use of increasingly sophisticated statistical tests of credit risk posed by loan applicants, however, render the realism of these respective explanations suspect.

We offer a novel and fundamentally different explanation for observations of discrimination and rationing in credit markets. Within the context of our model, we demonstrate that evidence of credit allocations consistent with lending discrimination can arise in efficient credit markets, in contrast to the reliance of traditional explanations on the a priori assumption that credit markets are inefficient. We also use our model to provide numerical examples which, based upon realistic parameter values, illustrate the extent to which discrimination, measured through the relative availability of mortgage credit to disadvantaged borrowers, occurs. These examples focus on two empirically significant traits of properties financed by such borrowers: volatility in the value of such properties and higher foreclosure costs per dollar of property value. (Note 4)

Our explanation uses a model of a representative credit market embedded in a traditional continuous-time economy exhibiting complete markets and arbitrage-free valuation. We augment this environment by incorporating the strategies chosen by lenders and borrowers in negotiating the terms of a standard secured loan. These strategies include the respective choices of these parties to exercise their options implicit in a loan of this type as a percentage of initial collateral value at the time of loan origination. The strategic timing of exercise by 
each party will depend, in part, on the properties of the asset(s) serving as collateral. Part or all of this collateral, in the case of a residential mortgage market, is the property being financed. Since each party will choose his optimal strategy in negotiating a loan, including the timing of his option exercise, credit market equilibrium can feature loans exhibiting contrasting terms or credit rationing if borrowers purchase properties which differ in the collateral risk they pose to lenders. If such borrowers also exhibit distinct demographic or other observable qualities, then a common belief among lenders in a relation between the demographic traits of a borrower and the collateral risk of his property will generate a non-cooperative equilibrium in which discrimination will be observed, even if all borrowers appear identical by standard measures of credit risk.

Empirical evidence of systematic discrimination most often arises in the American market for residential mortgages. Such evidence is normally provided by formal or informal tests of whether the loan terms or denial frequencies received by one class of borrowers, relative to another, arise only as a direct or indirect result of such demographic traits as the race, ethnicity or gender of members of this class. (Note 5) Under the condition that lenders all perceive a stable relation, whether objective or subjective in nature, between a given demographic class of borrowers and the properties of the representative asset(s) securing their loans, we show that endogenous discrimination in the allocation of credit across different classes of borrowers will invariably be observed in market equilibrium. (Note 6) Unlike the inefficient equilibria exhibited in earlier approaches involving lender preferences or asymmetric information, however, our equilibrium arises in an economy with complete markets and arbitrage-free pricing. Conditional on this common belief of lenders, moreover, this equilibrium is consistent with an efficient allocation of credit across all borrowers.

The paper is organized as follows. We review the relevant previous research on equilibrium credit discrimination in the next section. Our model is described in Section 3. Analytical and numerical results are presented in Section 4. Section 5 offers a discussion of the implications of our model for both applied economic theory and public policy. Concluding remarks appear in the final section.

\section{Literature and Context}

The significance of this paper is in its resolution of the anomaly of discriminatory loan terms and credit rationing within a market satisfying the classical assumptions of finance theory. This section compares and contrasts our analysis to previous economic explanations of lending discrimination and credit rationing.

The traditional framework for explaining idiosyncratic lending patterns across different borrowers was pioneered by Hodgman (1960) and Freimer \& Gordon (1965), and refined in subsequent models by Jaffee \& Modigliani (1969), Barro (1976), and others. Differential access to credit ultimately arose, in these papers, from an exogenous inability of lenders to accurately price credit risk among individual borrowers. While able to predict lending patterns, which, for a suitable choice of parameters, could approximate empirical evidence of discrimination, these models could not generate endogenous credit market equilibria exhibiting discrimination based on observable borrower characteristics. 
In a subsequent approach, Stiglitz \& Weiss (1981) analyzed the endogenous decisions of lenders who, owing to the assumed presence of either adverse selection or moral hazard, could price risk to individual borrowers only on the basis of the average degree of credit risk of a group of borrowers. Loan terms, as a result, could vary across groups of borrowers and under extreme circumstances a group could experience the rationing of credit. Hart and Moore (1998), Martin (2008), and Park (2000), among many others, subsequently refined this approach to include the influence of monitoring costs and renegotiation in the design loan contracts.

Models based on asymmetric information are unsuitable, however, in explaining discrimination owing to observable traits distinguishing borrowers of equal credit risk. Equilibrium allocations of credit in these models necessarily depends on the unobservable characteristics of borrowers directly germane to their individual credit risk. Like those models relying on an exogenous ability to price risk, the market equilibria in asymmetric information models are necessarily inefficient in allocating risk.

Our model and results are distinguished in two fundamental ways from this earlier research. First, we endogenously derive both the existence and magnitude of equilibrium lending discrimination using only the classical assumptions of financial asset-pricing models. Second, we show that, in our model, these assumptions generate equilibria consistent with an efficient allocation of credit risk.

The model used in this paper, more specifically, is devoid of any exogenous source of market failure and instead assumes an economy with complete capital markets, common knowledge of the actuarial risk of default on the part of both borrowers and lenders, and, as a result, arbitrage-free pricing of credit risk. Our model augments these assumptions by explicitly incorporating both the strategic aspects of mortgage loan negotiation and the presence of observable demographic traits which, while independent of the measure of credit risk in standard statistical underwriting methods, may differentiate borrowers in the common perception of risk held by lenders. This allows us to apply the familiar replication techniques of contingent claims analysis to accurately value, from origination to the maturity date, the mortgage contract to a representative lender and borrower.

Consequently, it also allows us to determine whether systematic variation in loan terms and credit availability across demographically distinct groups of borrowers requires the assumption of market inefficiency or whether they can be explained solely in terms of the strategic exercise of the embedded options each party holds in a standard mortgage loan. In turn, this allows us to conclude whether either idiosyncratic lender preferences or market inefficiency is necessary for lending discrimination to be observed, as asserted by traditional explanations of lending discrimination, or whether discrimination can simply result from the economic incentives of lenders and borrowers inherent in actual mortgage lending.

Our paper is also related to research on the (non-strategic) exercise of the default and prepayment options possessed by mortgage borrowers. Kau, Keenan, Muller, \& Epperson (1995), Archer, Ling, \& McGill (1996), and Deng, Quigley, \& Van Order (2000) have used contingent claims methods to value both fixed-rate and adjustable rate-mortgage contracts. 
These option-based models generate predictions for default based on the current value of a property relative to the discounted value of continuing to service its mortgage. Our paper differs from these in analyzing the option to default in the strategic context of loan negotiation between lender and borrower. We consequently expand this traditional option-based literature on mortgage termination to include strategic options, deriving the endogenous response of the lender's offer of loan terms and supply of mortgage credit to the strategic timing of the decision of the borrower to exercise his default or prepayment options as well as to the characteristics of the property which secures his loan.

Finally, our approach to the design and valuation of mortgage contracts parallels that of the "strategic debt service" literature, as exemplified by Anderson \& Sundaresan (1996) and Archaya et al. (2006). These authors use a game-theoretic extension of the standard Merton debt (1974) to study the effect on debt pricing of strategic renegotiation and bankruptcy costs. Our model differs from those, however, in using collateral risk as the basis for loan valuation and in its focus on the degree of lending discrimination as an endogenous function of collateral risk.

\section{The Model}

\subsection{Assumptions}

We model the loan contract negotiated by a representative borrower and lender as a stochastic differential game in which the observed terms of that contract emerge from the conditions of a perfect Markov equilibrium in that game. (Note 7) The type of contract we consider is a standard fixed-rate mortgage loan secured by the property being purchased and displaying an arbitrary amortization structure over a finite term to maturity. Specific versions of this general contract include the common mortgage contracts found in virtually all jurisdictions within the United States and elsewhere. (Note 8)

This contract specifies that the lender advances a sum to the borrower, who in return promises to make a scheduled sequence of coupon payments to the lender over the life of the loan. The borrower defaults on the mortgage if he fails to make a payment as agreed and the lender can then foreclose upon the borrower, seizing the property securing the contract and reselling it. The initial market value of that property is common knowledge to both agents but that value evolves randomly and consequently has, at each moment, an uncertain future value. The borrower, through his equity ownership, receives a measurable flow of (housing) services from the property, much like the flow of dividends to a corporate stock. The value of housing services, exogenous depreciation and any investment by the borrower in the property are all also assumed to be common knowledge.

Two aspects of standard mortgage contract are particularly relevant to our analysis. First, the value of the past flow of housing services cannot be retrieved by the lender in the event of default. Since the prospect of these flows was capitalized in the initial market value of the property, that value is excluded from the security available to the lender at the time of default, creating an inverse relationship between the conditional value of the loan collateral prior to maturity of the mortgage and the magnitude of housing services received by the mortgagor. 
Second, both borrowers and lenders will exercise the respective options embedded in the mortgage loan, such as the borrower's options to default or prepay and the lender's option to foreclose following default, at a time serving only their own interests. Owing to the non-contingent nature of the mortgage contract, neither party can fully hedge or offset relative losses sustained as a result of their counterparty's decisions but instead choose their own exercise strategies as a best response to those of that counterparty.

The optimal strategies of each player are determined through the valuation functions of each party about their respective claims on the asset serving to secure the loan. Since the economy is assumed to have complete markets, we apply the standard arbitrage-free valuation method to derive a pair of linked partial differential equations which must be satisfied by the values of these contingent claims. Defining the state space of the game to be the support of all asset values and dates relevant to the decisions of the borrower and lender, we employ recursive methods to endogenously derive, through these differential equations, those subsets of this state space which represent the strategy spaces of each of the parties. A numerical solution for the game is obtained by finding those sequential paths in the state space which represent the "best-reply" strategies of the parties and which, in turn, determine market equilibrium. Each choice of parameter values for the market yields a distinct and unique equilibrium. The comparison of the properties of interest exhibited by alternative equilibria are compared and through this comparison we characterize lending discrimination in the form of loan terms and the volume of credit exchanged between lenders and different classes of borrowers.

\subsection{Specification}

Consider a representative credit market in which participants trade, over dates $t$, a single risky asset of value $a(t)$. We interpret this asset as a representative residential property, but it can be interpreted as any risky asset suitable to other applications. Participants also have access to the market for a riskless asset with maturity $T$ and return $r$. The market operates in a continuous time economy satisfying the assumptions of the classical asset valuation environment. In particular, this economy has a complete filtered probability space $[\Omega, \mathfrak{T}, P]$, where $\Omega$ represents the space of events in this economy, $\mathfrak{I}$ represents the corresponding filtration, a set of sequential sigma algebras $\{\mathfrak{T}\}_{0 \leq t \leq T}$ representing information available to traders at time $t$, and $P$ is the actuarial probability measure over asset value and defined on $\Omega$. All market participants observe each $\mathfrak{I}_{t}$, which is common knowledge, and base all decisions at each date $t, 0 \leq t \leq T$, on this observation. Asset markets are complete with respect to the source of risk arising in our representative credit market and, consequently, the representative market for credit upon which we focus exhibits arbitrage-free valuation.

We assume for simplicity the residential mortgage contract has a standard nonrecourse form under which a lender advances a unit of credit to a borrower at date 0 for which the borrower is obligated to remit both continuous coupon payments at a constant rate $c$ until maturity $T$ and a terminal balance $C(T)$, where $C(t)$ represents the unpaid loan balance at all dates $t \in$ $[0, T]$. (Note 9) The rate premium $\gamma$ paid by the borrower is determined by the constant coupon rate specified in the contract relative to the riskless rate $r$. Since different residential properties exhibit distinct qualities relevant to their market value, we assume that all 
properties eligible as collateral belong to a suitably defined set $\Phi$, and that the vector of qualities distinguishing different properties are indexed by the vector $\varphi \in \Phi$. (Note 10) The value of the representative property at date $t, a(t)$, evolves according to the diffusion

$$
a(t)=\alpha(a, t) d t+\sigma a(t) d z(t)
$$

where $z(t)$ is a standard Brownian motion, $\alpha(a, t)$ is the expected drift at all $t$ and $\sigma$ measures the conditional volatility of this value. The value of any specific property $\varphi$ evolves as a case of (1) distinguished by a unique value $\sigma_{\varphi}$ of the volatility parameter.

Each borrower is assumed to display an exogenous degree of an innate trait, observable by the lender but intrinsically independent of any measure of the borrower's risk of default. We index this trait over some bounded subset $\Theta$ of the real line and denote the degree of this trait displayed by an arbitrary borrower by $\theta \in \Theta$. We will, for the purposes of realism in our treatment of discrimination in mortgage lending, interpret these qualities as demographic in nature. In any application of our model intended to generate the same pattern of loan terms as in any particular set of observations of demographic discrimination in an actual mortgage market, these qualities may include ethnicity, gender, race and other traits relevant to these particular observations.

Finally, we choose to model the economic source of discrimination as the perceived volatility $\sigma$ in the diffusion (1) describing the evolution of the market value of the generic property. If a lender objectively perceives a correlation between the observable degree to which a borrower exhibits the common demographic trait, $\theta$, and those characteristics of the specific property this borrower wishes to finance, $\varphi$, then under these circumstances, the lender acts as if the effective volatility in the intertemporal value of this property as a function of the borrower's degree, $\theta$. Our specification of this correlation can be written in very general terms as the composition function,

$$
\widetilde{\varphi}=\varphi(\theta)
$$

and, consequently, the lender's perception of risk or the lender's uncertainty over the future value of the property will be:

$$
\sigma=\sigma(\widetilde{\varphi}(\theta))
$$

We will use oto denote this volatility parameter for notational simplicity in what follows but we will use the perceived risk on the part of the lender in (2) to solve for the presence and magnitude of lending discrimination below.

The initial value of this asset is common knowledge, as is the evolution of this value in (1). Since these features are exogenous and cannot be influenced by either party to the loan, neither moral hazard nor adverse selection are present in this market. While he services the loan, the borrower receives a continuous flow of housing services, $\pi(a, t)$, measurable in market terms. Foreclosure, following a failure by the borrower to pay $c$ at any date $t$, results in sale of the asset. The lender receives $\max [a(t)-b(a, t), 0]$ from this sale, where $b(a, t)$ is the liquidation cost incurred by the lender, and the borrower receives any residual funds exceeding the unpaid balance $C(t)$. 
Negotiation of the terms of the loan contract is represented by the choice of intertemporal strategies by borrower and lender. Their respective strategy spaces include choice of the timing of any exercise of the range of options normally embedded in the loan covenants. The principal element of the space of the lender is, in the current paper, his specification of the initial amount of credit advanced, $C(0)$, and, contingent on default, the date of foreclosure. (Note 11) The principal strategic elements chosen by the borrower are the timing of both his exercise of the option to default or to prepay the existing loan balance. The strategy of the lender and of the borrower are each selected to maximize, subject to the strategy of his counterparty, the value of his contingent claim on the asset collateralizing the loan.

Denote by $L(a, t)$ the values to the lender of payments received from the borrower and from his option to foreclose and denote by $B(a, t)$ the value of the borrower's position, inclusive of his default and prepayment options in the contract. Consistent with the traditional features of our economy, application of standard arbitrage pricing methods yield the respective functions $L(a, t)$ and $B(a, t)$, generating these values for all possible combinations $(a, t)$. Solutions for these value functions, under each choice of parameters, represent the respective values of the debt and equity claims on the asset in a perfect Markovian equilibrium.

Solutions to these functions satisfy a pair of partial differential equations, linked by the best-reply strategies selected by each party and by the respective boundary conditions for each equation. This pair of equations is

$$
\begin{gathered}
r L=\left(\frac{1}{2}\right)(a \sigma)^{2} L_{a a}+(r a-\pi) \mathrm{L}_{\mathrm{a}}+c+L_{\mathrm{t}}, \\
r B=\left(\left(\frac{1}{2}\right)(a \sigma)^{2}(a \sigma)^{2} B_{a a}+(r a-\pi) B_{a}+c+B_{t}\right),
\end{gathered}
$$

with the corresponding boundary conditions

$$
\begin{aligned}
& L(\check{a}, t)=\max \{0, \breve{a}-\eta(\breve{a}, t)\}, \\
& \pi(\check{a}, t)-c+E_{t} B^{*}(\breve{a}, t)=0,
\end{aligned}
$$

and

$$
\begin{gathered}
L^{*}(\hat{a}, t)=C(t), \\
\pi(\hat{a}, t)-c+E_{t} B^{*}(\hat{a}, t)=0,
\end{gathered}
$$

The term $E_{t}(\bullet)$ is the expectations operator under the unique equivalent martingale measure induced by our assumption of complete markets and $B^{*}(a, t)=\left(e^{r} d t\right) B(a+d a, t+d t)$ and $L^{*}(a, t)=\left(e^{r} d t\right) L(a+d a, t+d t)$ are the respective risk-adjusted values of the claims of the borrower and lender, discounted at the riskless interest rate. Denoting by $\overline{\bar{B}}(a, t)$ and $\overline{\bar{L}}(a, t)$ the respective values of the parties' claims if the loan terminates through the exercise of an option by either party, the terms $\check{a}$ and $\hat{a}$ are the respective asset values triggering default and prepayment $b$ the borrower. At these values the functions $B(a, t)$ and $L(a, t)$ satisfy the value-matching and smooth-pasting criteria. The value-matching condition 
requires the borrower's value function to be continuous at the respective asset value inducing him to default at date $t, \breve{a}$, or to prepay at date $t$, $\hat{a}$, as defined respectively by

$$
\begin{aligned}
& B(\breve{a}, t)=\overline{\bar{B}}(\breve{a}, t), \\
& B(\hat{a}, t)=\overline{\bar{B}}(\hat{a}, t),
\end{aligned}
$$

while the smooth-pasting condition requires the first derivatives of $B(\bullet)$ and $\overline{\bar{B}}(\bullet)$ to be continuous at these same points. The lender's value function is required to satisfy analogous criteria at those distinct points where he would exercise his option to foreclose or, if the game allows this option, to call.

\subsection{Numerical Solution Procedure}

Since the finite maturity of the loan precludes an analytical solution, we characterize market equilibrium through numerical solutions for the valuation equations and boundary conditions (3)-(8). We use a recursive finite difference procedure to obtain these solutions in which the respective sets of strategies of the lender and borrower are interpreted as subsets of the discrete grid constituting, for numerical purposes, the underlying state space of our game $A$ xT defined over all possible states $(a, t)$. (Note 12) Any strategy chosen by either party is, in this context, a region (subset) of $A \mathrm{xT}$, such that any realization of the state $(a, t)$ within them triggers the exercise of an option by one of these respective parties

A feasible strategy for the lender consists of his choice of the initial balance, $C(0) \in A$, at the origination of the loan and, conditional on default, his choice of a date for initiating foreclosure. Since the lender will always choose to foreclose immediately at default in this model, all of his feasible strategies belong to the closed set $A x\{0\}$. Similarly, the strategy of the borrower can be represented in terms of the union of two closed regions of $A x T$, the first of which is $D$, comprised by all the states at which the borrower will optimally choose to default, and the second of which is $P$, in which the borrower will prepay the outstanding loan balance should his property become sufficiently valuable. Determining whether, at each point in the state space, each party would prefer to continue or terminate the loan, these regions are found by recursively calculating the grid points at each date $t-1$ that are accessible from each prior grid point representing date $t, 0{ }_{-}^{<} t \leq T$. A numerical solution for the unique equilibrium of the game, given the choice of parameter values describing the exogenous features of the market, is then obtained by using these values to find the unique "path," for each point $(a, t)$ in our discrete approximation of the state space $A x T$, which constitutes best-reply strategies for the parties. The characterization of discrimination in the market is then obtained by comparing the terms and volume of credit for the loan contract in the equilibria generated by each of our choices of alternative parameter values. 


\section{Results}

When lenders perceive a direct relation between the degree of one or more demographic traits displayed by borrowers with the salient characteristics of the property securing the loan, best-reply strategies and equilibrium loan contract values to market participants will be conditional on the degree to which a given borrower displays one or more of the observable demographic traits assumed. Since empirical data on mortgage lending discrimination restricts borrowers to belong to one of a very small number of different demographic classes, we will present our results in terms of the restriction that exactly two such classes exist or, equivalently, that $\Theta$ has only two elements. (Note 13) We will also, only for purposes of simplicity, also assume that the respective members of each such class wish to finance a property with volatility $\sigma$, the quality distinguishing properties in (1)-(2), common to the property of every other member of their class but distinct from those financed by members of the other class. These assumptions are simultaneously reflected in equation (2) for each of the two values of $\theta$.

The presence and magnitude of equilibrium discrimination, as a consequence, can be deduced directly through the comparing the equilibrium loan terms for each of the two classes of borrowers. Selection of alternative sets of values of the parameters determining the stochastic evolution of the property common to the choice of class and those representing the institutional features of the market allow us to compare the properties of the strategies and debt and equity values in the equilibrium arising for each class. Such comparisons allow us to measure the relative difference between loan terms and the volume of credit exchanged in each equilibrium. We can, therefore, numerically assess the existence and magnitude of systematic lending discrimination in these comparisons.

Since the features most frequently cited in empirical evidence of lending discrimination, such as in analyses of HMDA data in the U.S., are comparisons of the amount of credit obtained at loan origination and selected loan terms, we focus the presentation of our results on these two properties of credit market equilibrium. (Note 14) We use the initial loan balance, which is also the current value of the loan to the lender $C(0)$, to measure the amount of credit and the rate premium $\pi$ to represent the terms of the loan and compare these values across the equilibria corresponding to alternative sets of parameters describing the exogenous features of the credit market. The existence of a perceived correlation between classes of loan borrowers distinguished by traits unrelated to credit risk and the parametric characteristics of the diffusion process describing the value of the representative asset securing the equilibrium loan contract for each class yields different loan terms and balances offered to the members of each such class.

The exogenous features of the market we consider include the instantaneous mean $\alpha(a, t)$ and, conditional on the borrower's type, $\theta$, the volatility $\sigma(\theta)$ exhibited over time by the collateral asset; the net flow of value $\pi(a, t)$ accruing to equity in the asset; the cost $b(a, t)$ incurred by the lender in liquidating the asset in the event of foreclosure; and any cost $f(C(t))$ incurred by the borrower should he prepay the loan. We assume, for simplicity in the presentation and discussion of the parametric cases below, that the net revenue flow from the asset $\pi(a, t)$, 
liquidation costs $b(a, t)$ and prepayment costs $f(C(t))$ are all independent of time and homogeneous in their arguments. These allow us to represent conveniently the initial loan balance as a percentage of the initial value of the asset. We interpret as annual the per-period values for the riskless rate and rate premium, the asset volatility and the maturity of the loan as a convenience for the reader. Finally, we note that the equilibrium value of the rate premium on a given mortgage, $\gamma$, is determined through the no-arbitrage condition for all debt of the risk corresponding to this mortgage.

We present our results as equilibrium values of the initial loan balance $C(0)$, per corresponding rate premium $\gamma$, for alternative values of a chosen exogenous variable, holding constant all other parameters at benchmark values. The benchmark values underlying the results presented below are, respectively, a riskless annualized interest rate of $r=.03$, an annualized proportional volatility (standard deviation) in the value of the collateral asset of $\sigma$ $=.2$; an instantaneous flow of value to equity $\pi$ of ten basis points, a maturity $T$ of five periods, a one basis point flow of coupon payments $c$; and both liquidation $b(a, t)$ and refinancing $f(C(t))$ costs of zero. We also specify six gridpoints, or equivalently five "periods," over the state space A xT for our calculations of the numerical solutions to equations (2)-(7).

Owing to their empirical significance to minority housing, we choose as our respective exogenous variables the relative magnitude of foreclosure costs per-dollar of property value (Note 15) and the volatility of property prices in minority neighborhoods relative to majority neighborhoods. (Note 16)

We first consider the influence of liquidation costs on the equilibrium amounts and terms of credit and show that, above a certain threshold rate premium, the lender will rationally ration credit. Table 1 illustrates this by depicting how loan balances $C(0)$ vary with successive two percentage point increases in the corresponding equilibrium rate premium $\gamma$, as the costs $b$ of asset liquidation in foreclosure increase from a "low value" (10\%) to a "high" value (30\%). Higher balances correspond to higher rates in each case, but, as expected, higher liquidation costs reduce the initial loan balance at each rate premium. Averaged over the 12-percentage point range of rates, initial balances are $86.34 \%$ and $78.37 \%$ at the respective low and high liquidation costs, which is approximately an eight-percentage point difference. Note, in particular, that, as liquidation costs become sufficiently high, rate increases beyond a threshold point (8\% in this example) elicit virtually no increases in initial balances. Applications for higher balances, albeit at higher rate premia, would be denied in this case, resulting in the observation that the volume of mortgage credit available to minority applicants is significantly less than that volume offered to other applicants with equivalent degrees of measured credit risk. 
Table 1. Loan terms: effects of liquidation costs

\begin{tabular}{|l|l|l|}
\hline RATE PREMIUM & CASE ONE $(\boldsymbol{b}=\mathbf{1 0} \%)$ & CASE TWO $(\boldsymbol{b}=\mathbf{3 0} \%)$ \\
\hline & $C(0)$ & $C(0)$ \\
\hline 0.02 & 71.70 & 57.60 \\
\hline 0.04 & 82.70 & 65.00 \\
\hline 0.08 & 89.00 & 68.00 \\
\hline 0.10 & 93.00 & 70.70 \\
\hline 0.12 & 95.50 & 71.80 \\
\hline 0.14 & 97.20 & 71.90 \\
\hline
\end{tabular}

Note. Table 1 illustrates the influence of liquidation costs on equilibrium lending terms. Case One shows that, for relatively low costs ( $b=10 \%$ ) of liquidating the asset at default, the initial loan balance is $71.7 \%$ at a rate premium of $2 \%$. This balance increases monotonically with this rate until it reaches $98.3 \%$ of the asset value at a $14 \%$ rate. Case Two illustrates, however, that higher liquidation costs reduce both the amount of credit available at each rate premium as well as rate at which that amount increases at each successively higher rate. Liquidation costs of $30 \%$ reduce the initial loan balance to only $57.6 \%$ at a two percent premium while the increases in the balance for equal rate increases steadily decline until, at a rate premium of $10 \%$, the balance reaches only $71.90 \%$. True credit rationing occurs after this point, with subsequent rate increases producing no increase in credit. Higher rates provide no increase in value for the lender because liquidation costs imply that the increased risk of default they induce outweighs any increase in the value of higher coupon payments.

Table 2 illustrates the influence of price volatility on credit available at each rate. When volatility is relatively "low" ( $\sigma=15 \%$ ), for each increase in rates balances increase, but at a rate that decreases sharply from $14 \%$ at a $2 \%$ premium to $1 \%$ at a $12 \%$ premium. Doubling the volatility, as in Case Two, reduces the amount of credit available at each corresponding rate at an average decline of 10.2 percentage points relative to the lower volatility. Successive rate increases accompany balances increasing, again at a decreasing rate.

Table 2. Loan terms: effects of asset price volatility

\begin{tabular}{|l|l|l|}
\hline RATE PREMIUM & CASE ONE $(\boldsymbol{\sigma}=\mathbf{1 5} \%)$ & CASE TWO $(\sigma=\mathbf{3 0} \%)$ \\
\hline & $C(0)$ & $C(0)$ \\
\hline 0.02 & 78.10 & 58.10 \\
\hline 0.04 & 88.70 & 73.70 \\
\hline 0.06 & 93.60 & 82.10 \\
\hline 0.08 & 96.20 & 87.50 \\
\hline 0.10 & 97.70 & 91.10 \\
\hline 0.12 & 98.70 & 93.70 \\
\hline 0.14 & 99.20 & 94.40 \\
\hline
\end{tabular}

Note. Analogously, Table2 illustrates the influence of annual volatility in asset value on equilibrium lending terms. Case One shows that, for relatively low volatility $(\sigma=10 \%)$, the initial loan balance is $78.10 \%$ at a rate premium of $2 \%$. Credit available to the borrower increases monotonically with this premium until it reaches $99.2 \%$ of the asset value at a $14 \%$ rate. This increase in credit, however, exhibits a sharply decreasing rate of increase, from approximately a $14 \%$ growth in initial balance as the premium rises from a value of $2 \%$ to $4 \%$, to only $1 \%$ growth as the premium rises from a value of $12 \%$ to $14 \%$. Higher volatility ( $\sigma=30 \%$ ), as expected, reduces the amount of credit available, at each corresponding value of the rate premium, to an average balance of $83 \%$ relative to an average of $93.4 \%$ at the lower volatility. 
We now illustrate, in the last set of our selected results, the effects on the availability of credit from simultaneous variation in the volatility of asset value and costs of liquidating that asset at foreclosure. Table 3 measures these effects through four parametric combinations corresponding to those in Tables 1 and 2. In the first case, loan terms are shown for "low" ( $b=10 \%)$ and "high" ( $b=30 \%)$ liquidation costs, conditional on the "low" value $(15 \%)$ of price volatility. The second case repeats this same increase in liquidation costs, but now at the "high" volatility value (30\%).

Table 3. Loan terms: combined effects of liquidation costs and asset price volatility

\begin{tabular}{|l|l|l|l|l|l|}
\hline \multicolumn{2}{|c|}{ VOLATILITY (15\%) } & \multicolumn{3}{c|}{ VOLATILITY (30\%) } \\
\hline & $\mathbf{b}=. \mathbf{1 0}$ & $\mathbf{b}=. \mathbf{3 0}$ & & $\mathbf{b}=. \mathbf{1 0}$ & $\mathbf{b}=. \mathbf{3 0}$ \\
\hline & $\mathbf{C ( 0 )}$ & $\mathbf{C ( 0 )}$ & & $\mathbf{C ( 0 )}$ & $\mathbf{C ( 0 )}$ \\
\hline 0.0200 & 0.7690 & 0.7050 & 0.0200 & 0.5230 & 0.4990 \\
\hline 0.0400 & 0.8400 & 0.7660 & 0.0400 & 0.6610 & 0.5600 \\
\hline 0.0600 & 0.8700 & 0.7910 & 0.0600 & 0.7400 & 0.6030 \\
\hline 0.0800 & 0.8840 & 0.7980 & 0.0800 & 0.7890 & 0.6340 \\
\hline 0.1000 & 0.8900 & 0.8040 & 0.1000 & 0.8220 & 0.6540 \\
\hline 0.1200 & 0.8940 & 0.8090 & 0.1200 & 0.8440 & 0.6480 \\
\hline 0.1400 & 0.8970 & 0.8130 & 0.1400 & 0.8590 & 0.6420 \\
\hline
\end{tabular}

Note. The effects on equilibrium loan terms of simultaneous variation in the volatility of asset value and costs of liquidating that asset at foreclosure are illustrated in Table 3. Loan terms, again represented by the rate premium and corresponding initial loan balance, are shown for four combinations of parameter values. In the first case, loan terms are shown for the same "low" $(\mathrm{b}=10 \%)$ and "high" ( $\mathrm{b}=30 \%)$ liquidations costs as considered in Table 1 , conditional on the annual price volatility of $15 \%$ used for Case One in Table 2 . The second case shows these same loan terms for the same two values of liquidation cost, but now conditional on the annual price volatility of $30 \%$ used for Case Two in Table 2.

Three aspects of our results are particularly notable. First, the data in Tables 1-2 clearly illustrate, as expected, that loan balances at any given rate are considerably lower for borrowers when lenders incur higher liquidation costs at constant price volatility or when price volatility increases at constant costs of liquidation. Table 3 illustrates, in addition, that the adverse impact on credit caused by a given increase in liquidation costs or volatility is significantly worsened by a respective increase in volatility or liquidation costs. Consider, for example, that the approximately 6 percentage point decline in average balances caused by a given rise in liquidation costs from $10 \%$ to $30 \%$ at an annual volatility of $15 \%$ increases to an approximately 22 percentage point decline in average balances for the same increase in liquidation costs at an annual volatility of 30\%, a difference of 16 percentage points.

Second, the response of balances to small variations in loan rates also differs in these same situations. Our results in Table 3 suggest that a given increase in liquidation costs will have a significantly smaller effect on the rate balances grow, per unit increase in loan rates, when price volatility is relatively low than when it is high. When annual volatility is $15 \%$, for example, an increase in liquidation costs from $10 \%$ to $30 \%$ corresponds to a 20 basis point decrease in the average growth of balances per unit rate increase, but the same increase in 
liquidation costs at an annual volatility of $30 \%$ corresponds to a 454 basis point decrease.

The third, and most striking, feature of our results is that not only can the "rationing" of credit occur to different borrowers, based on the characteristics of the assets used to collateralize their respective loans, but, for possible, if extreme, parameter values in the market, increases in the rate premiums that rationed borrowers are willing to pay can actually reduce the loan balance they receive. A comparison of Tables 1-3 illustrates that, as rate premiums rise, the successive increases in balances decline at any combination of liquidation costs and price volatility. This declining responsiveness of balances can appear as incipient or actual credit rationing. However, when liquidation costs and price volatility are both high, Table 3 demonstrates that, above a threshold rate of $10 \%$, each successive increase of two percentage points in rates actually causes credit to decline by 60 basis points.

\section{Discussion}

Set in a classical economy devoid of market failures and idiosyncratic preferences, our results show that lending discrimination on a demographic basis can arise when rational lenders risk-price credit to maximize returns on mortgage loans. To borrowers with identical measures of credit risk. Such discrimination on the basis of disparate treatment takes the form of loan terms featuring increasing costs of borrowing borne by these borrowers as risk to lenders posed by the collateral property of such borrowers increases.

This result poses a significant difficulty for explanations of observed discrimination that attribute such discrimination to the preferences, irrationality or cognitive limitations of lenders, or to the presence of such market failures as adverse selection or moral hazard. It also casts some doubt on the robustness of evidence of discrimination when this evidence is based on econometric tests that fail to include those property characteristics identified by our model as influences on the costs of borrowing.

Assume that observers external to a given credit market find a repeated pattern of discrimination by lenders correlated with the display by borrowers of a certain demographic feature bearing no intrinsic relationship to credit risk. This behavior by lenders will appear to these observers as inconsistent with the purely economic incentives lenders would face in a competitive and efficient credit market. Under these circumstances, observers and most analysts will conclude that this market is either allocationally inefficient or inequitable with respect to the welfare of disadvantaged borrowers, or both. (Note 17)

When asked to explain this disparate treatment of borrowers, these analysts would likely cite one or more of the traditional explanations of lender behavior described earlier, such as demographic prejudice, irrationality, behavioral limits on cognition leading to systematic errors in the decisions made by lenders or other such characteristics. They might alternatively cite reasons based on possible flaws in the credit market itself, such as a common inability of lenders to accurately underwrite loans, perhaps owing to the use of technology inadequate for the accurate measure of credit risk or to the presence of adverse selection or moral hazard on the part of borrowers, or to distortions to lender incentives arising from secondary markets, or to some other type of market failure asserted to be present in this market and possibly in most 
or all credit markets.

While these explanations appear entirely reasonable in many cases, our results demonstrate that, contrary to popular belief, none of them constitutes a necessary condition for discrimination to occur. (Note 18) Observations of discrimination can occur even if rational and competent lenders, devoid of demographic preferences, simply react to market incentives in an efficient credit market. These observations arise as a consequence of overlooking those sources of credit risk posed to borrowers from the properties securing the loans made to minority loan applicants, even when the measured credit risk of these applicants is identical to that of other applicants.

Equilibrium discrimination arises in our model for two reasons. First, lenders and borrowers both behave strategically in order to maximize the value accruing to them from their position in the loan contract. This strategic behavior includes decisions by each party whether and at what time to exercise the options, embedded in the loan contract, over which they exert control. (Note 19) Either party to the contract will choose a strategy, which includes these exercise decisions, in his own interest and to the detriment of his counterparty. (Note 20) The counterparty, of course, foresees his opponent's incentives and takes them into account when selecting his own strategy. A promise by either party to refrain from actions, such as the exercise of one of his options, that are costly to the counterparty and to act instead in their mutual interest is not credible and is treated as such in the selection of strategies by each party.

Second, both parties are aware that the intertemporal flow of housing services to the borrower and ongoing property depreciation constitute sources of economic value. The borrower, as equity holder, receives this flow of services as long as he services his loan. The lender, however, cannot retrieve the values of past service flows in the event of default. While the prospect of this flow was capitalized, in the classical environment of our model, into the market value of the property at the time of loan origination, the value of this flow is unavailable as security to the lender at the time of a default. Consequently, the collateral value of the borrower's property is diminished to the extent that this flow is higher or the likelihood of its loss through default is greater.

These two features guarantee that those borrowers, even with a standard measure of credit risk identical to other borrowers, who finance properties which pose relatively greater collateral risk to the lender will bear correspondingly higher costs of borrowing in equilibrium. As an example, a lender would prefer that a borrower who defaults does so at the last moment the value of the liquidated property securing his loan fully covers the unpaid loan balance. Since property values can always appreciate, however, the borrower will always choose to delay his irreversible exercise of this option beyond that time. This delay could be lengthy, causing a significant loss to the lender, such as when the value to the borrower of property services exceeds his costs of servicing the mortgage. The probability of this loss is, obviously, increased when the volatility of this property's price is greater. Similar, the lender will foresee a greater magnitude of loss when the flow of these services or his cost of property liquidation is higher. 
The case in which discrimination is observed to occur on purely demographic grounds can now be seen to arise immediately when lenders in this market also share a common belief in a correlation between one or more demographic traits distinguishing a borrower and any characteristics of the property that borrower wishes to finance that pose, relative to the properties of other borrowers, a higher risk of loss to the lender in the event of default. (Note 21) These include greater degrees of price volatility, higher percentage foreclosure costs and other features of the disadvantaged borrower's property that increases this risk. Whether using current econometric procedures or more subjective methods to assess lending data, external observers will correctly see a "pattern and practice” of disparate treatment in regard to the costs of borrowing borne by minority borrowers but their traditional explanations of this pattern and practice may well overlook the legitimate economic incentives faced by lenders in an efficient market.

Consider an example in which the neighborhoods of a city are segregated on the basis of one or more features of a minority group and a majority group. This segregation could have occurred from a preference by the members of one or both groups for various locational qualities, such as geographical proximity to other members of their class relative to the other class, or be caused from sources entirely exogenous to the mortgage market, such as the differential treatment of these two groups in regard to the provision by local government of public or private services in their neighborhoods, or from a variety of other reasons beyond the influence of lenders. If lenders believe that depreciation rates are higher in a given minority neighborhood than in a majority neighborhood, perhaps owing to property crime arising from the relative scarcity of police services in the former neighborhood, or are risk-averse and more uncertain about the appreciation of property prices or foreclosure and liquidation costs in the former neighborhood, perhaps owing to relatively fewer sales or costlier, less frequent or less accurate property appraisals in that neighborhood, or for other reasons, then lenders will perceive that the collateral value of the representative property will be less in that neighborhood than in a majority neighborhood. As a consequence, even if they share similar measures of credit risk with their majority counterparts, prospective minority homebuyers will only be able to obtain mortgages that have significantly less attractive terms than those offered to majority homebuyers.

\section{Concluding Remarks}

The objective of this paper is to provide an explanation for the extensive evidence of demographic discrimination in mortgage and other credit markets using contingent-claims valuation and based entirely on the classical assumptions of financial economics. Such an explanation, if successful, would show whether any of the alternative presumptions of preferences marked by demographic prejudice or irrationality, cognitive bounds on decision-making, or market failures and allocational inefficiency in credit markets, underlying existing explanations are prerequisites to explain lending discrimination. It would also, by implication, determine whether current financial regulations or other public policy measures are necessarily useful in enhancing economic efficiency in these markets.

The model in this paper is the first example of such an explanation. Based on an economy 
exhibiting complete markets, arbitrage-free pricing and common knowledge of all relevant parameters, the model incorporates an explicit consideration of the respective choice of strategies by a representative lender and borrower, including the strategic exercise of the options embedded in the generic form of loan contract observed in actual mortgage markets. When lenders share a common perception that an observable demographic trait distinguishing one group of borrowers from groups is directly related to the relative degree of risk posed to lenders by the characteristics of the properties which secure the mortgages of these borrowers, then, in the presence of rational lenders and absent any source of market failure, our results demonstrate that credit market equilibria will invariably exhibit discrimination in the loan terms and cost of credit to the members of this group. Such discrimination occurs even when, under standard underwriting procedures, the representative members of different groups have similar measures of individual credit risk.

While this conclusion is of real significance to the theory and modeling of mortgage and other credit markets, it also has significant implications for empirical applications of financial economics based on current data and for the design of incentive-based regulations and other public policies intended to mitigate both the efficiency and welfare inequities of such discrimination. These implications concern both the reasons for lender behavior and their response to incentives and the robustness of evidence of lending discrimination based on statistical inferences drawn from actual lending data.

It is important to note that our results in no way deny the existence or possible ubiquity of various types of lending discrimination, such as the disparate treatment of minority mortgage applicants. Neither does it deny that such discrimination can and likely does often arise from demographic bias in lender preferences, errors in lending decisions arising from behavioral limitations or from various sources of market failure. What our results do, however, is demonstrate that these qualities are only sufficient, rather than necessary, conditions for lending discrimination to occur. Evidence of lending discrimination, as a result, cannot imply that lenders are irrational, prejudiced, systematically err in their lending decisions or otherwise perversely respond, relative to standard economic predictions, to market incentives. Nor can such evidence imply the presence of any efficiency failures in credit markets.

Our results also demonstrate the potential fragility of evidence of discrimination based on current econometric analyses of HMDA or similar data. HMDA data, for example, fails to include observations of any features of those properties or other assets securing mortgage loans relevant to the collateral risk to which borrowers are exposed. If the design of econometric tests requires holding constant or equal the credit risk of given pairs or groups of sample borrowers, then the omission of observations or variables measuring the collateral risk from those features could mean a failure to properly control for the full measure of the credit risk posed to a lender from an individual borrower.

Current statistical evidence of lending discrimination, as a consequence of both results, is subject to misinterpretation and is, in and of itself, an insufficient basis on which to design or adopt financial regulations intended to enhance the economic efficiency of residential mortgage lending. The results in this paper also encourage caution in implementing policies 
to mitigate inequities in the relative welfare of disadvantaged borrowers. Using only traditional economic models and empirical evidence which may be less than robust in ascertaining the nature of the incentives to which lenders respond in actual mortgage markets, redistributive policies may be effective in their purpose or may alternatively reduce the welfare of all borrowers through a distortion of the incentives to lend and borrow.

More generally, this paper also demonstrates the feasibility of applying the contingent claims method of valuation to the analysis and explanation of differences in credit available to borrowers based on factors other than the conventional statistical measures of individual credit risk used in underwriting mortgage loans. The advantages of using a complete market and complete information-common knowledge environment are compelling in attaining a benchmark measure of the efficiency of lending and the allocation of credit based on the use of standard mortgage and other debt contracts. It permits one to describe equilibrium option exercise strategies by both borrowers and lenders that are independent of risk attitudes, endowments and divergent expectations about the future value of the assets securing these contracts. It enforces consistency between collateral characteristics such as dividend-like flows of services from these assets and no-arbitrage variations in their market value. It offers the promise of an operational method of calculating the respective values of a particular mortgage loan, at any moment, to both lender and borrower under empirically plausible conditions. Finally, it could also, as a consequence, provide the means of accurately measuring both the credit risk ultimately borne by both borrowers and lenders and the disparities in the costs of credit to borrowers belonging to different demographic groups. This has the potential to enhance both the accuracy of underwriting methods and the efficacy of public policy in reducing any existing inefficiencies in credit allocation and in reducing or eliminating inequities in the relative welfare of affected borrowers.

\section{References}

A.B.A. (2012). Fair lending: legal foundations. In ABA Toolbox on Fair Lending, American Bankers Association, Washington D.C.

Acharya,V., Huang, J., Subrahmanyam, S., \& Rangarajan, K. (2006). When does strategic debt-service matter? Economic Theory, 29(2), 363-378. https://doi.org/10.1007/s00199-005-0035-9

Anderson, R. W., \& Sundaresan, S. (1996). Design and valuation of debt contracts. The Review of Financial Studies, 9(1), 37-68. https://doi.org/10.1093/rfs/9.1.37

Archer, W., Ling, D., \& McGill, G. (1996). The effect of income and collateral constraints on residential mortgage terminations. Regional Science and Urban Economics, 26(3), 235-261. https://doi.org/10.1016/0166-0462(95)02115-9

Avery, R., Beeson, P., \& Calem, P. (1997). Using HMDA data as a regulatory screen for fair lending compliance. Journal of Financial Services Research, 11(1), 9-42. https://doi.org/10.1023/A:1007937422673

Avery, R., Brevoort, K., \& Canner, G. (2007). Opportunities and issues in using HMDA data. 
Journal of Real Estate Research, 29(4), 351-380.

Barro, R. (1976). The loan market, collateral and rates of interest. Journal of Money, Credit and Banking, 8(1), 439-456. https://doi.org/10.2307/1991690

Bensoussan, A., Siu, C., Yam, S., \& Yang, H. (2014). A class of non-zero-sum stochastic differential investment and reinsurance games. Automatica, 50(3), 2025-2037. https://doi.org/10.1016/j.automatica.2014.05.033

Bressan, A., \& Priuli, F. (2006). Infinite horizon noncooperative differential games. Journal of Differential Equations, 227(1), 230-257. https://doi.org/10.1016/j.jde.2006.01.005

Brueckner, J., Calem, P., \& Nakamura, L. (2016). House-Price Expectations, Alternative Mortgage Products and Default. Journal of Money, Credit and Banking, 48(1), 81-112. https://doi.org/10.1111/jmcb.12291

Calem, P. S., Firestone, S., \& Wachter, S. M. (2010). Credit impairment and housing tenure status. Journal of Housing Economics, 19(3), 219-232. https://doi.org/10.1016/j.jhe.2010.07.003

Calem, P., Lambie-Hanson, L., \& Nakamura, L. (2015). Information Losses in Home Purchase Appraisals. Working Paper 15-11, Federal Reserve Bank of Philadelphia. https://doi.org/10.2139/ssrn.2646084

Courchane, M., Nebhut, D., \& Nickerson, D. (2000). Lessons learned: Statistical techniques and fair lending. Journal of Housing Research, 11(2), 277-295. [Online] Available: http://www.innovations.harvard.edu/sites/default/files/jhr_1102_courchane.pdf

Deng, Y., Quigley, J., \& Van Order, R. (2000). Mortgage terminations, heterogeneity and the exercise of mortgage options. Econometrica, 68(2), 275-307. https://doi.org/10.1111/1468-0262.00110

Ding, L. (2014). The Pattern of Appraisal Bias in the Third District During the Housing Crisis. Working Paper 14-10. Federal Reserve Bank of Philadelphia. [Online] Available: https://pdfs.semanticscholar.org/c3c7/7dd5bf4025f4ac9f7960e83e255cbd58d7b6.pdf

Federal Reserve Board. (2005). Federal fair lending regulations and statistics overview. In Federal Reserve Board, Interagency Fair Lending Examination Procedures, CA Letter 04-8, Washington D.C. [Online] Available: https://www.federalreserve.gov/boarddocs/supmanual/cch/200601/fair_lend_proc.pdf

Federal Reserve Board. (2015). The 2014 Home Mortgage Disclosure Act Data. Federal Reserve Bulletin, 101(4). Washington D.C. [Online] Available: http://www.federalreserve.gov/pubs/bulletin/2015/pdf/2014_HMDA.pdf

Freimer, M., \& Gordon, M. (1965). Why bankers ration credit. Quarterly Journal of Economics, 79(3), 397-410. https://doi.org/10.2307/1882705

Gerardi, K., Lambie-Hanson, L., \& Willen, P. (2013). Do Borrower Rights Improve Borrower Outcomes? Evidence from the Foreclosure Process. Journal of Urban Economics, 73(1), 1-17. 
https://doi.org/10.1016/j.jue.2012.06.003

Grinstein-Weiss, M., Clinton, K., \& Carrillo, S. (2015). Homeownership, the Great Recession, and Wealth: Evidence From the Survey of Consumer Finances. Housing Policy Debate, 25(3), 419-445. https://doi.org/10.1080/10511482.2014.971042

Hart, O., \& Moore, J. (1998). Default and renegotiation: a dynamic model of debt. Quarterly Journal of Economics, 113(1), 1-41. https://doi.org/10.1162/003355398555496

Hodgman, D. (1960). Credit risk and credit rationing. Quarterly Journal of Economics, 74(2), 258-278. https://doi.org/10.2307/1884253

Immergluck, D. \& Smith, G. (2006). The external costs of foreclosure: The impact of single-family mortgage foreclosures on property values. Housing Policy Debate, 17(1), 57-79. https://doi.org/10.1080/10511482.2006.9521561

Jaffee, D., \& Modigliani, F. (1969). A theory and test of credit rationing," American Economic Review, 59(5), 850-872. [Online] Available: http://www.jstor.org/1810681?seq=1\#page_scan_tab_contents

Joint Economic Committee of Congress Special Report. (2007). Sheltering Neighborhoods from the Subprime Foreclosure Storm. United States Congress Documents Archive. [Online] Available:

https://www.jec.senate.gov/archive/Documents/Reports/subprime11apr2007revised.pdf

Kau, J., Keenan, D., Muller, W., \& Epperson, J. (1995). The valuation at origination of fixed-rate mortgages with default and prepayment. Journal of Real Estate Finance and Economics, 11(1), 5-36. https://doi.org/10.1007/BF01097934

LaCour-Little, M. (1999). Discrimination in mortgage lending: a critical review of the literature. Journal of Real Estate Literature, 7(1), 15-50. https://doi.org/10.1023/A:1008616203852

Landvoigt, D., Piazzesi, M., \& Schneider, M. (2015). The Housing Market(s) of San Diego. American Economic Review, 105(4), 1371-1407. https://doi.org/10.1257/aer.20111662

Lang, W., \& Nakamura, L. (1993). A model of redlining. Journal of Urban Economics, 33(2), 223-234. https://doi.org/10.1006/juec.1993.1014

Martin, A. (2008). Adverse selection, credit, and efficiency: the case of the missing market. Universitat Pompeu Fabra CREI Working Paper Series. https://doi.org/10.2139/ssrn.1143309

Merton, R. C. (1974). On the pricing of corporate debt: the risk structure of interest rates. The Journal of Finance, 29(2), 449-470. https://doi.org/10.1111/j.1540-6261.1974.tb03058.x

Park, C. (2000). Monitoring and structure of debt contracts. The Journal of Finance, 55(5), 2157-2195. https://doi.org/10.1111/0022-1082.00283

Reid, C., \& Laderman, E. (2009). The Untold Costs of Subprime Lending: Examining the Links among Higher-Priced Lending, Foreclosures and Race in California. Working Paper, 
Research Department, Federal Reserve Bank of San Francisco. [Online] Available: https://iasp.brandeis.edu/pdfs/Author/reid-carolina/TheUntoldCostsofSubprimeLending3.pdf

Stiglitz, J., \& Weiss, A. (1981). Credit Rationing in Markets with Imperfect Information. American Economic Review, 71(2), 393-410.

Trottenberg, U., Oosterlee, C., \& Schuller, A. (2000). Multigrid. New York: Academic Press.

Turner, M., \& Skidmore, F. (2000). Mortgage lending discrimination: a review of existing evidence. The Urban Institute, Washington D.C. [Online] Available: http://citeseerx.ist.psu.edu/viewdoc/download?doi=10.1.1.17.2543\&rep=rep1\&type=pdf

\section{Notes}

Note 1. Discrimination in credit markets occurs when borrowers of one type receive different terms or volume of available credit than other types of borrowers, holding all else equal, on the basis of one or more qualities distinguishing borrower types. Descriptions of different forms of lending discrimination can be found in A.B.A. (2012) and an overview of current U.S. fair lending regulations and statutes can be found in Federal Reserve Board (2006).

Note 2. Comprehensive surveys of both popular and economic explanations of mortgage lending discrimination appear in LaCour-Little (1999) and Turner \& Skidmore (2000).

Note 3. Neither approach is, however, fully satisfactory. The first approach implies that management of financial institutions systematically fails to maximize the value of shareholder equity while the second does not apply to

Note 4. The greater relative variance in property prices in low-income and minority neighborhoods is documented in Leiberman (2009), Landvoigt, Piazzesi, \& Schneider (2015) and Grinstein-Weiss, Clinton, \& Carrillo (2015) while evidence for the relative magnitude of percentage foreclosure costs is surveyed in Joint Economic Committee of Congress Special Report (2007).

Note 5. Econonmetric evidence attributing discrimination, usually in terms of disparate treatment, to differences in demographic traits requires that such tests control for differences in borrower credit risk, but do not take into account the qualities of the property collateralizing a given mortgage. Avery, Brevoort, \& Canner (2007) survey alternative econometric methods of testing for demographic discrimination in mortgage lending as well as the properties of corresponding lending data, which are primarily drawn from information provided by lenders under the 1975 Home Mortgage Disclosure Act (HMDA). A description of HMDA data can be found in Federal Reserve Board (2015).

Note 6. While such efficiency is, of course, conditional on the use of the standard form of mortgage contract appearing in the U.S. and elsewhere, our model applies any credit market featuring standard debt contracts with finite maturities, fixed terms and rates and limited contingent covenants. 
Note 7. Bressan \& Priuli (2006) and Bensoussan, Siu, Yam, \& Yang (2014) analyze perfect Markov equilibria in stochastic differential games with properties similar to those of our model.

Note 8. Our mortgage contract subsumes any fixed-rate mortgage with a finite maturity, recourse provisions and standard foreclosure provisions. For example, although we treat the mortgage contract in our model as non-recourse, our results can easily be applied to partial or full recourse mortgage loans by reinterpreting the asset securing the loan to include portions of the borrower's portfolio in addition to the property being financed.

Note 9. Our model and results could, as easily, apply to mortgage contracts with recourse through the reinterpretation of a as the portfolio of assets, the value of which is given by (1), serving as collateral for the mortgage loan.

Note 10. The index $\varphi$ could be interpreted as a vector and, the set $\Phi$ as a continuum but for simplicity we respectively treat them as a scalar and discrete. Analogously, we treat the set $\Theta$ as discrete and the index $\theta$ as a scalar.

Note 11. This space could, in a more complex version of the model, be augmented to include several additional options, including the right to call the loan.

Note 12. A standard reference to the implementation of the finite-difference method we use is Trottenberg, Oosterlee, \& Schuller (2000).

Note 13. The binary values of $\Theta$ can be interpreted to designate "majority" and "minority" borrowers, "white" and "black" borrowers, "male" and "female" borrowers, and so on, depending upon the nature of the data to which the model is applied.

Note 14. Prominent examples of such analysis include Avery, Beeson, \& Calem (1997), Avery, Brevoort, \& Canner (2007).

Note 15. Among the reasons that per-dollar foreclosure costs are greater in minority neighborhoods are (i) ssignificant fixed costs to lenders initiating foreclosure procedures, including legal requirements for documentation, court procedures and minimum times mandated by states for statutory redemption by all homeowners (Gerardi, Lambie-Hanson, \& Willen 2013); and additional uncertainty about recovery costs owing to both the externalities on house values and greater variance in appraisals of those values arising from the higher relative incidence of foreclosed properties in these neighborhoods (Ding, 2014).

Note 16. Relatively greater volatility in minority property prices arises from several sources, including relatively greater effects of the business cycle on labor income of minorities and disparities in the availability of mortgage credit and/or federal loan guarantees to low-income and minority borrowers (Grinstein-Weiss, Clinton, \& Carrillo, 2015); a significantly higher rate of default arising from the concentration of alternative mortgage products and high LTV loans in minority neighborhoods (Brueckner, Calem, \& Nakamura (2016); externalities on local home prices from the high incidence of default in such neighborhoods (Immergluck \& Smith (2006); and cycles in the degree of appraisal bias toward properties in minority neighborhoods (Lang \& Nakamura, 1993; Calem, Firestone, \& Wachter, 2010). 
Note 17. Courchane, Nebhut, \& Nickerson (2000), among others, examine the robustness of findings of disparate treatment obtained from various econometric tests applied to both public data and proprietary underwriting data from private banks.

Note 18. Owing to the assumptions in our model, note that variation in loan terms cannot occur through economic price discrimination, search or other transactions costs generating price dispersion when the market in question conforms to the market in our model.

Note 19. Note that the reasons we cite are ultimately the result of the generic, non-contingent form of loan contract used in most real credit markets.

Note 20. The "zero-sum" nature of these actions assumes that the value of each participant's position in the loan contract cannot be affected by binding side-payments or other transactions involving credible commitment or cooperation.

Note 21. Observe, from equations (7)-(10), that, since the composition function (2) describing housing price volatility is continuous, decreasing values of this correlation commensurately reduce the costs of a disparity in loan terms received by demographically distinct borrowers.

\section{Copyright Disclaimer}

Copyright for this article is retained by the author(s), with first publication rights granted to the journal.

This is an open-access article distributed under the terms and conditions of the Creative Commons Attribution license (http://creativecommons.org/licenses/by/3.0/). 